\title{
Consideraciones sobre la vinculación entre regionalismo y multilateralismo en materia de comercio internacional
}

\section{Considerations on the link between regionalism and multilateralism in international trade}

\author{
Carolina Lourdes Rodríguez Aguilera
}

Universidad Simón Bolívar, Venezuela

Autor corresponsal: rodriguezcarol@usb.ve

Fecha de recepción: 01 de Octubre de 2017 - Fecha de aceptación: 15 de Abril de 2018

Resumen: La propuesta de reflexionar acerca de la vinculación entre regionalismo y multilateralismo en materia de comercio internacional, es un tema de mucho interés, que refleja una interdependencia compleja en las relaciones internacionales (Keohane; Nye, 1988), y es objeto de profundos debates. Por las razones expuestas, la metodología utilizada en el presente estudio se tipifica como documental descriptiva, pues, atendiendo a Hernández et al. (2010: 80): "Es útil para tomar con precisión los ángulos y dimensiones de un fenómeno, suceso, comunidad, contenido o situación". Este enfoque permitió obtener información relevante sobre las características de los acuerdos comerciales regionales y multilaterales. Asimismo, se enmarca en una investigación de tipo analítica, según Hurtado (2012), trata de entender las situaciones en términos de sus componentes. Por consiguiente, este trabajo se estructuró partiendo de la revisión de diversas fuentes de información bibliográficas y de organizaciones internacionales especializadas.

Palabras Claves: regionalismo; multilateralismo; integración económica; comercio internacional

\begin{abstract}
The proposal to reflect on the link between regionalism and multilateralism in international trade is a theme of great interest, reflecting a complex interdependence in international relations (Keohane; Nye, 1988), and is the subject of much debate.

For the above reasons, the methodology used in the present study is typified as descriptive documentary, because according to Hernández (2010: 80): "It is useful for accurately taking the angles and dimensions of a phenomenon, event, community, content or situation." This approach allowed us to obtain relevant information on the characteristics of regional and multilateral trade agreements. It is also part of an analytical research, according to Hurtado (2012), trying to understand situations in terms of their components. Therefore, this work was structured on the basis of a review of various sources of bibliographical information and specialized international organizations.
\end{abstract}

Key Words: regionalism; multilateralism; economic integration; international trade 


\section{Introducción}

La conducta de los Estados a través de su participación simultánea en Acuerdos Subregionales de Integración y en Acuerdos Multilaterales de Comercio merece especial atención como objeto de estudio. Como se sabe el sistema multilateral del comercio ha garantizado la existencia de los acuerdos comerciales regionales como excepción a la cláusula de la nación más favorecida.

Cabe destacar que la cláusula de la nación más favorecida desarrolla el principio de no discriminación que está contenido en el artículo I del General Agreement on Tariffs and Trade (GATT) o Acuerdo General sobre Aranceles Aduaneros y Comercio, que prescribe que los países miembros de la Organización Mundial del Comercio (OMC) deben conceder inmediata e incondicionalmente a todo producto similar originario de los territorios de todos los demás miembros de la OMC o a ellos destinado cualquier ventaja, favor, privilegio o inmunidad concedidos a un producto originario de otro país o a el destinado. Sin embargo, el sistema multilateral de comercio GATT/OMC ha admitido excepciones a la regla de no discriminación. Los acuerdos regionales son un ejemplo, algunos adoptados bajo el artículo XXIV del GATT; artículo V del General Agreement on Trade in Services (GATS) de servicios, o la Cláusula de habilitación (enabling clause).

Podría pensarse que los países han optado por la integración económica como un instrumento válido para mejorar su participación en el escenario internacional, y de esa manera, se espera procurar mayores beneficios, bajo el precepto que juntos constituyen un actor más fuerte para negociar. Pueden mencionarse como ejemplos, el Mercado Común del Sur (MERCOSUR), el Mercado Común Centroamericano (MCCA), la Comunidad Andina (CAN), el Tratado de Libre Comercio de América del Norte (TLCAN), y la Asociación Latinoamericana de Integración (ALADI).

Sin embargo, los desafíos y obstáculos que se presentan en el comercio internacional, en especial, en sectores sensibles como el agrícola o el industrial, bosquejan la discusión sobre la importancia que los procesos de integración estén consolidados. Adquiere valor, no sólo el interés por incrementar el comercio de bienes y servicios, sino también, fomentar la cooperación entre los países, así como, mejorar el nivel de vida de la población.

Los resultados del referéndum del Brexit en junio de 2016, la reciente decisión de Estados Unidos de no ratificar el Acuerdo Transpacífico y el emplazamiento a renegociar el Tratado de Libre Comercio de América del Norte, dan cuenta de la complejidad de estas relaciones.

En el ámbito de un proceso de integración regional y en el marco multilateral, la necesidad de establecer reglas aparece como una condición necesaria, aunque no suficiente, hace falta genuino esfuerzo de parte de sus impulsores, y resultados para las economías de los países partícipes, para las industrias, y un progreso del nivel de vida de la población. Por los motivos expuestos, como punto central en este trabajo de investigación, se pretende explicar la vinculación entre el regionalismo y el multilateralismo desde la perspectiva comercial.

\section{Marco teórico}


En este apartado se procura hacer una breve exposición sobre la relación entre el regionalismo y el multilateralismo, que es motivo de discusión ante la aparición de preocupaciones y dificultades entorno al curso que pueden estar tomando las negociaciones relativas al comercio internacional. Es importante aclarar que se analizará dicha relación, en primer lugar, a través de una aproximación conceptual sobre regionalismo y multilateralismo.

Son variadas las expresiones que se han encontrado en la bibliografía que se ha consultado sobre este objeto de estudio. Desde distintas perspectivas, se utilizan términos como: "opciones encontradas", "amigos o rivales", "convergencia necesaria", "son los Acuerdos Comerciales un escalón o un obstáculo para el sistema comercial?" (Oyarzun de La Iglesia, 1998; Van Kleveren, 2001), incluso metafóricamente Pascal Lamy (Director General de la OMC, 2005-2013) se refirió en un discurso en Bangalore, India (2007), relativo a los Acuerdos regionales como la "pimienta" en el "curry" multilateral.

El GATT, como la Organización Mundial del Comercio (OMC), reconoce el derecho de los países de concretar acuerdos regionales, pero los sujetan a un límite, no erigir barreras comerciales a terceros países. En ese orden, puede verificarse la coexistencia de distintos acuerdos comerciales regionales y la propuesta multilateral. Se distinguen tres tipos de normas: a) párrafos 4 a 10 del artículo XXIV del GATT, con disposiciones sobre el establecimiento y funcionamiento de uniones aduaneras y zonas de libre comercio; b) la cláusula de habilitación (Decisión de 1979) sobre trato diferenciado y más favorable entre países miembros en desarrollo; y, c) el artículo V del Acuerdo General de Comercio de Servicios, AGCS, sobre acuerdos en esta materia, para países desarrollados y en desarrollo.

Resulta útil esbozar a grandes rasgos, las principales observaciones que se pueden notar en la relación regionalismo-multilateralismo, con el objetivo de delimitar el marco conceptual en el cual se inscribe esta investigación. No se pretende en este estudio adelantar si uno es más efectivo que otro, parece como más relevante detectar y analizar los esfuerzos y las limitaciones, que propenden a la solución de estas situaciones, y eso exige impulso de todos los actores involucrados, incluyendo los Estados o grupos de Estados, particulares o empresas, y autoridades competentes. Por su parte, desde el escenario multilateral de comercio, se están planteando mecanismos para examinar la evolución de los acuerdos comerciales regionales en relación con los compromisos asumidos en la OMC:

En el segundo semestre de 2016 se notificaron a la OMC cuatro nuevos acuerdos comerciales regionales (ACR) y una adhesión a un ACR existente. En tres de los acuerdos, las partes son países de América Latina; en los otros dos, las partes son países de Asia y Europa. Tres de los acuerdos se notificaron en virtud de disposiciones de la OMC en materia de comercio de mercancías y comercio de servicios, mientras que los otros dos guardan relación únicamente con la liberación del comercio de mercancías. (OMC, 2017).

Es pertinente añadir que el 14 de diciembre de 2016, se cumplieron diez años del Mecanismo de Transparencia para los Acuerdos Comerciales Regionales, período en el cual, los Países Miembros de la OMC han examinado 143 Acuerdos Comerciales Regionales 
conjuntamente con la Secretaría de la OMC, (OMC, 2017). Por consiguiente, cuando las negociaciones multilaterales no avanzan o lo hacen lentamente, los países con intereses exportadores buscan opciones en acuerdos comerciales bilaterales y regionales. En suma, como ya se indicó, el sistema GATT/OMC autoriza la creación de áreas de libre comercio, mediante el artículo XXIV del GATT (bienes), el GATS (servicios) y la cláusula de habilitación de preferencias para los países en desarrollo.

\section{Sobre el regionalismo}

En los orígenes de la integración pueden figurar motivaciones históricas, la interdependencia entre los Estados para obtener equilibrios políticos y económicos entre sí y frente a otros Estados o bloques de Estados, como también, el interés en impulsar el desarrollo del país, y podría argumentarse también el desarrollo regional.

En ese contexto, es interesante destacar que el regionalismo, puede abordarse desde varios enfoques. Para comenzar, se puede inferir del regionalismo, una referencia espacial, geográfica, sin embargo, las negociaciones están demostrando el interés por desarrollar acuerdos con países y grupos sobre los cuales no hay proximidad geográfica.

Así también, un aspecto que se resalta del regionalismo es que tiene una carga "discriminatoria", en la medida que comporta acuerdos preferenciales entre un grupo de países vinculados voluntariamente, que como se puede advertir, podrían o no ser vecinos, y los múltiples fines para los cuales son concebidos, por ejemplo, podrían ser de diversa índole, comercial, económico, e incluir otras metas (Pérez Gabilondo, 2004). Estos acuerdos comerciales regionales constituyen pues, excepciones al principio de no discriminación y al tratamiento de nación más favorecida, preceptos fundamentales del sistema comercial multilateral (Lacarte y Granados, 2004).

Cuando la literatura se refiere a los acuerdos comerciales regionales, se observan dos opiniones marcadas, por un lado, cierta preocupación por los efectos comerciales que pueden generar, como puede ser desviación del comercio y la inversión, o que la proliferación de acuerdos de este tipo con sus variadas preferencias comerciales hace más complejo el sistema internacional de comercio. Por otro lado, hay quienes consideran que ese tipo de acuerdos pueden representar una pieza importante que confluya en un mejor sistema multilateral de comercio; observación que puede tener asidero ante la lentitud en los avances de la apertura multilateral; en este orden, podría alegarse que grupos regionales más pequeños pueden ser más eficaces para hacer frente a los temas en comparación con el proceso multilateral, y tener agendas más amplias (Moncayo, 1999). En ese sentido, el regionalismo, podría constituir una vía que a la larga conduzca a un comercio mundial más libre,

... avanzar de las economías nacionales a una economía mundial es simplemente demasiado grande. Es necesario dar primero pasos intermedios más pequeños y los cuasi bloques comerciales combinados con el comercio administrado bien pueden ser precisamente ese paso intermedio necesario. (Thurow citado por Di Tella, 2000:12).

Por su parte, Ferrer (2007) agrega que: 
Una de las manifestaciones de la globalización es la integración de los espacios regionales, como por ejemplo la integración europea, la integración entre Canadá y Estados Unidos, la presencia de México en el NAFTA...Compartir el espacio implica una serie de contactos humanos, físicos, materiales, una serie de intercambios donde se hace propicio avanzar en procesos más profundos de integración.

En América Latina puede observarse la generación de esquemas de integración tempranamente con la ALAC (1960), el Mercado Común Centroamericano (1960), el CARICOM (1968), y Acuerdo de Cartagena (1969), que corresponden a un tipo de regionalismo, fundamentados en objetivos de desarrollo a largo plazo, a través de un proceso de industrialización sustitutiva de las importaciones. Sin embargo, a partir de los años noventa, se desarrolló una nueva fase de integración en la región, conocido como regionalismo abierto, porque se propone ser un "building block" hacia la economía internacional y propicia la adhesión de nuevos miembros a los acuerdos (Moncayo, 1999: 42-43). De ahí la importancia de aprovechar las oportunidades que derivan de la geografía, la historia, la cultura, la cercanía para intentar desarrollar proyectos en común.

\section{Aproximación a la integración económica regional}

Es oportuno señalar que cuando se pretende estudiar la integración, es conveniente hacer algunas precisiones. Sobre el ámbito que puede abarcar, podrían referirse varias parcelas o áreas, trátese por ejemplo de integración económica, de espacios geográfico, social, entre otros. En el Diccionario de la Real Academia Española, se distingue, el vocablo integración, del latín Integratio, -onis, como relativo a la acción y efecto de integrarse.

Grien (1994: 42) destaca el aspecto abstracto de la palabra integración, vinculado a "recomponer", “acoplar", “combinar", "adherir", "sumar”, que va acompañada generalmente de algún atributo o adjetivo. En este trabajo nos referiremos a la integración económica regional. Ahora bien, cuando se intenta abordar la integración económica, puede entendérsela como un proceso, en este orden de ideas, hay autores que coinciden en esta percepción (Robertson, Tamamés, Ellsworth y Leith, citados por Chahín, 2004: 61-62).

De esta forma, la integración económica puede definirse como un proceso a través del cual, dos o más mercados nacionales se vinculan para formar un mercado mayor. En palabras de Ellsworth y Leith (2004:64) "la integración económica es la unificación de distintas economías en una sola más grande".

Dicho enfoque supone varios puntos a tomar en cuenta, por ejemplo, exige la realización de una serie de tareas y actividades para el logro de determinados objetivos, los cuales dependerán de la voluntad originaria de los Estados, que se vincularán con otros a través de la suscripción de un acuerdo internacional.

Entonces, a partir del pacto asumido por los Estados y de los compromisos acordados se espera que vayan adecuando sus comportamientos al logro de los fines comunes, que desde la 
postura que se ha introducido precedentemente, integración como proceso, sugiera un comportamiento progresivo. Además, la integración es parte de la política exterior de los Estados, y como política pública es generadora de relaciones de coordinación tanto a nivel nacional como internacionales. En este sentido, Josko de Guerón (citada por Romero M., 2009:21) sostenía que:

La política exterior es el resultado de la interacción de las demandas internacionales y nacionales al gobierno. Así pues, por una parte, el sistema internacional es el supuesto de la política exterior, sus características estructurales y coyunturales facilitan o inhiben la formulación de determinados objetivos, valorizan o desvalorizan medios y condicionan los resultados de la acción. Por otra parte, la política exterior, al igual que las otras decisiones gubernamentales, es un output del sistema político y como tal, condicionada por sus variables estructurales y coyunturales. (Josko de Guerón, citada por Romero M., 2009:21).

De esta forma, la integración regional puede tener dimensiones distintas, que puede trazarse como metas la constitución de acuerdos preferenciales, una zona de libre comercio, unión aduanera, mercado común, o unión económica y monetaria. En ese orden de ideas, puede explicarse que, los acuerdos preferenciales buscan la disminución de los aranceles entre los países miembros; la zona de libre comercio constituye un área por donde circulan libremente las mercaderías, sin pagar arancel y sin restricciones, pero los países mantienen autonomía de su política comercial con terceros países. En la unión aduanera, existe libre comercio entre un grupo de países y éstos aplican un arancel externo común para las importaciones procedentes de terceros países. Por su parte, el mercado común busca además de la libre circulación de bienes y servicios, movilidad de factores (capital, trabajo). La unión económica involucra metas adicionales como armonización de sus políticas económicas nacionales; $y$, la unión monetaria suma una política monetaria común (Mattli, 1999).

Por su parte, Moavro (1992:49) precisa la integración como:

El proceso mediante el cual dos o más países proceden a la eliminación de las barreras discriminatorias existentes entre ellos, para establecer un espacio económico común que resulta de la suma de los espacios económicos de cada uno de los participantes del proceso.

Por tanto, la integración regional constituye una opción que puede favorecer el logro de ciertos objetivos comunes entre los países, así como, ayudar la inserción internacional, más allá de que pueden constituir un avance gradual hacia el libre comercio mundial, en ese orden, puede verse la integración como un medio para alcanzar determinados objetivos. En consecuencia, la integración es un concepto de múltiples dimensiones, que está vinculado a la economía, el comercio, la política, lo social, la ciencia y la tecnología, teniendo como característica fundamental el diálogo, el consenso y la concertación entre los actores que forman parte de este proceso, condiciones idóneas para poder alcanzar los objetivos planteados. 
Cabe destacar que el economista Bela Balassa (1964:1), define a la integración de la siguiente manera:

Desde dos perspectivas: la integración como proceso, y la integración como situación de las actividades económicas en los términos siguientes: considerada como un proceso se encuentra acompañada de medidas dirigidas a abolir la discriminación entre unidades económicas, pertenecientes a diferentes naciones; y vista como una situación de los negocios, la integración viene a caracterizarse por la ausencia de varias formas de discriminación entre economías nacionales. (Balassa, 1964:1).

Esta posición admite varios puntos a tomar en cuenta, por ejemplo, exige la realización de una serie de tareas y actividades para el logro de determinados objetivos, los cuales obedecerán a la voluntad originaria de los Estados, que se relacionarán con otros a través de la subscripción de un acuerdo internacional.

Mientras que Tugores (1999:173) hace énfasis en la integración como:

El proceso mediante el cual los países van eliminando sus características diferenciales. Teóricamente podría ir eliminándose entre los países, para ir hacia una economía global integrada, pero por razones políticas y económicas los procesos de integración tienen lugar de forma parcial, es decir implicando a un número de países normalmente reducido.

Como puede notarse, los autores mencionados coinciden en mostrarse de acuerdo con la integración económica como un proceso multidimensional que exige la adecuación de las políticas económicas de los países a los objetivos de integración, que pueda permitir su inserción internacional, y a la vez, reconocen las dificultades que radican en las asimetrías nacionales.

Sin embargo, el camino es exigente, es preciso destacar las reflexiones sobre el regionalismo en América Latina que presentó la CEPAL, donde se señalan como principales obstáculos al desarrollo del regionalismo, a) la persistencia de barreras no-arancelarias entre los países de la región; b) las frecuentes excepciones a los aranceles externos comunes, esto es, no existe estabilidad en la forma de enfrentar la competencia externa o problemas de coyuntura interna; c) la inadecuada infraestructura regional y las instituciones regionales y nacionales débiles; d) la limitada coordinación de las políticas macro y sectoriales; e) la escasez de mecanismos de promoción del desarrollo económico y social, que lo relaciona con el problema de la falta de cohesión social; y, f) la asimetría en los procesos de crecimiento regional (Mattos, 2005:45).

Vale tener presente que, si la integración regional implica proyectos de asociación entre un número menor de países en comparación con un grupo multilateral, podría argumentarse que sería una ventaja a la hora de negociar y encarar la resolución de conflictos. De ahí la importancia de los principios rectores de los acuerdos comerciales, que sirven de guía a los organismos encargados de aplicar o interpretar el derecho. 
Puede observarse, que, tanto desde un ámbito regional como multilateral, las normas pretenden regular las relaciones comerciales y dar cierto ambiente de estabilidad, sin embargo, la realidad puede tornarse híbrida. Es interesante observar que, cuando un grupo de países acuerdan vincularse a través de un proceso de integración regional económica, generan un espacio mayor de intercambio económico comercial y un conjunto de normas que regularan esos intercambios, y podría esperarse que en la medida en que se avance y se consolide un espacio regional de integración, empiecen a aparecer otras áreas de interés como la materia migratoria, laboral, energética, de infraestructura, entre otras (Obaya, 2005:15).

En síntesis, el proceso de integración puede constituir una oportunidad para potenciar el logro de objetivos que los países por sí mismos o no podrían alcanzar, o llevaría más tiempo y costos realizarlos.

\section{Las modalidades institucionales de la integración}

En materia de integración económica regional se observan dos modelos de enfoque institucional, el intergubernamental y el supranacional. Al respecto, en el modelo institucional intergubernamental, los Estados conservan el poder y las iniciativas de decisión y acción. Mientras que, en el modelo institucional supranacional, los actores políticos (Estados), transfieren (mandato originario) determinadas actividades y competencias hacia la nueva institución supranacional, que pasaría a convertirse en agente especializado de integración, con autonomía respecto a sus mandantes (Mattli, 1999).

La integración puede aparecer entonces, no sólo como un proceso económico de eliminación de barreras o restricciones al comercio entre los Estados, sino también, adquirir un carácter especial en las relaciones que los países diseñan que puede llegar a comprender instituciones u organizaciones de integración intergubernamental o supranacionales, así como, puede comportar la producción de un derecho de la integración o derecho comunitario y un sistema de solución de controversias propio. Incluso, puede agregarse, que en ese propósito podrían darse combinaciones, a través de instituciones comunitarias y nacionales, en especial si se toma en cuenta que las autoridades nacionales de los países que participan en un proyecto integracionista, deben ser garantes de los compromisos acordados, por lo que, puede decirse que hay una responsabilidad compartida en el cumplimiento de los deberes y en la vigilancia de los derechos.

\section{Sobre el multilateralismo}

Desde la perspectiva multilateral, es oportuno destacar que, el sistema multilateral del comercio actual, comprende un conjunto de normas de derecho internacional público, así como, instituciones que rigen el intercambio de bienes y servicios. Las instituciones pretenden cumplir una función muy importante con el objetivo de dotar de previsibilidad y orden a las relaciones comerciales internacionales, como estaba previsto en el GATT 47, y ahora, luego de los Acuerdos de Marrakech, se extiende hacia otros sectores como los servicios y la propiedad intelectual. 
En ese sentido, el marco jurídico del sistema multilateral del Comercio, está conformado por los Acuerdos de Marrakech que contienen los compromisos negociados por los países. Es preciso señalar que los Acuerdos de Marrakech son el resultado de la Ronda Uruguay y se conforman de: a) Acuerdo de la OMC; b) GATT 1994: Acuerdos Anexos en materia de comercio de mercancías; Acuerdo sobre servicios; Acuerdo sobre aspectos de la propiedad intelectual relacionados con el comercio ADPIC; Entendimiento para la solución de diferencias; Mecanismo de revisión de políticas comerciales; Acuerdos comerciales plurilaterales; Decisiones y Declaraciones de Marrakech. Así como también, la estructura institucional que administra dicho sistema, la OMC (Pérez Gabilondo, 2004:32).

Desde sus orígenes el GATT (en la actualidad la OMC) ha permitido a los países miembros formar áreas de libre comercio y uniones aduaneras, como una excepción al principio fundamental de no discriminación, contenido en la disposición sobre la nación más favorecida del artículo I del Acuerdo General sobre Aranceles Aduaneros y Comercio.

El movimiento de las relaciones comerciales internacionales se ha caracterizado por la proliferación de acuerdos comerciales regionales (ACR). Para tener una idea del vertiginoso crecimiento de los acuerdos comerciales, es preciso referirnos a la información que recoge la página web de la OMC (2017), según la cual, el número de Acuerdos Comerciales Regionales no ha dejado de aumentar desde principios de los años 90. No es menor el dato que muestra esa institución, al señalar que, en el período comprendido entre 1948 y 1994, el GATT recibió 124 notificaciones de ACR (en la esfera del comercio de mercancías), y desde el establecimiento de la OMC en 1995, se han notificado más de 400 acuerdos adicionales que abarcan el comercio de mercancías o de servicios.

Adicionalmente, merece especial atención que muchos miembros de la OMC siguen participando en nuevas negociaciones de ACR. Hay acuerdos bilaterales y plurilaterales, entre varios Miembros de la OMC. Es el caso de las negociaciones que se están llevando a cabo en la región de Asia y el Pacífico para perfeccionar un Acuerdo de Asociación Transpacífico, en las que actualmente participan 12 partes; las negociaciones en Asia entre los miembros de la Asociación de Naciones del Sudeste Asiático (ASEAN) y otros seis Miembros de la OMC con los cuales la ASEAN tiene acuerdos vigentes (el Acuerdo de Asociación Económica Amplia Regional); la Alianza del Pacífico, en América Latina, de la que actualmente forman parte Chile, Colombia, México y el Perú; y el Acuerdo Tripartito, en África, entre las partes en el Mercado Común de África Oriental y Austral (Common Market for Eastern and Southern Africa, COMESA), la Comunidad del África Oriental (CAO) y la Comunidad para el Desarrollo del África Meridional (Southern African Development Community, SADC). Además, el número podría ser mayor si se proyectan los Acuerdos regionales que aún no han sido notificados, y si se cristalizan las negociaciones en curso de nuevos acuerdos. Como recientemente reseña la OMC, con la entrada en vigencia del ACR entre Mongolia y el Japón, notificado en junio de 2016, todos los Miembros de la OMC tienen ya un ACR en vigor (OMC, 2017).

Ante ese contexto, vale tener presente el señalamiento de Pascal Lamy (OMC, 2007), en Bangalore, cuando expresó que “... la proliferación de acuerdos comerciales regionales podría complicar considerablemente el entorno comercial con la creación de una red de normas incoherentes". Y advirtió que: 
...dado que los acuerdos comerciales regionales son una realidad insoslayable y teniendo en cuenta que la OMC no excluye este tipo de acuerdos, en determinadas condiciones, el reto que nos enfrentamos hoy es el de garantizar que contribuyan al buen funcionamiento del sistema mundial del comercio, reduciendo al mínimo el riesgo de que disminuyan el bienestar global y limiten las economías de escala.

En ese sentido, concuerda la Declaración de Doha, por la que los Miembros de la OMC llamaron la atención sobre la necesidad de iniciar negociaciones para aclarar y mejorar las disciplinas y los procedimientos relativos a los acuerdos comerciales regionales. Por una parte, los acuerdos regionales podrían tener un rol importante en la liberalización del comercio, pero también, existe la preocupación para conseguir una relación armoniosa entre el proceso multilateral y los procesos regionales (OMC, 2017).

Sobre el particular, se ha destacado que "la complementariedad entre los distintos niveles de integración es compleja; las agendas subregionales, regionales, hemisféricas y globales abordan y ponen énfasis diferentes en diversos aspectos. En ellos, las arenas y los escenarios en que se desarrollan impactan a los más diversos actores. De allí que es esencial el producir coordinación. Sin ella, cada uno de los procesos será visto desde una perspectiva sectorial sin ningún tipo de vínculos entre ellos, y en definitiva, se reafirma la fragmentación y las reducidas capacidades de concertación transnivel desde lo nacional a lo global" (Consejo General de la OMC, 2007).

Por las razones expuestas, cuando se comienza a analizar la relación entre el regionalismo y el multilateralismo, emergen varios aspectos y matices, así como posturas, que son interesantes de abordar. Desde una perspectiva optimista, podría señalarse que, en tanto el supuesto de los acuerdos regionales y multilaterales es la liberación del comercio, en el primero, en un área espacial más reducida por el número de miembros involucrados que en los segundos, podría entonces pensarse que los pactos regionales serían un complemento o "building block" que propendería al libre comercio mundial que se plantea en el ámbito multilateral (Rojas Aravena, Altman Josette, 2006: 4).

Incluso podría suponerse que la labor conjunta hacia la eliminación de obstáculos al comercio entre los países partes del grupo regional, sería más manejable hacia ese objetivo, que en un plano multilateral. Sin embargo, aunque desde un análisis teórico parece una consecuencia lógica, se reconoce que también en los grupos regionales se presentan situaciones que exigen un esfuerzo de coordinación y trabajo.

En el escenario económico comercial internacional coexisten acuerdos comerciales regionales y multilaterales. El mismo se muestra como interdependiente, en el sentido de que se observa flujos de comercio, dinero, personas y comunicaciones; así como, el establecimiento de diversos regímenes internacionales que establecen principios, normas, reglas y procedimientos en determinadas áreas, entre los Estados, con la finalidad de regular una gran variedad de intereses. Estos regímenes pretenden dar previsibilidad, orden y transparencia a las relaciones internacionales. 
Nada nos asegura que las relaciones que denominamos interdependientes puedan caracterizarse como de beneficio mutuo, y no implican necesariamente la existencia de una relativa igualdad en cuanto a los recursos disponibles o los beneficios obtenidos por los diferentes actores, pudiendo darse situaciones de interdependencia compleja, simétrica o asimétrica, según el caso. (Moncayo, 1999:40).

No debe dejarse de lado que Keohane y Nye (1988) destacan que los valores que animen a los actores también incidirá en las tomas de decisiones como la naturaleza de la relación. A esto se puede agregar, el grado de compromiso y la voluntad para ejecutar los mandatos.

Los teóricos de los regímenes internacionales, buscan explicar los beneficios funcionales proporcionados por las reglas e instituciones internacionales, como puede ser la reducción de la incertidumbre, mejoramiento de la comunicación, acceso a la información (Hurrell, 1992; Hasenclever, Mayer y Volker Rittberger, 1999). En líneas generales, los regímenes internacionales, en las áreas determinadas que regulan, como en los Acuerdos comerciales de integración regional o multilateral, establecen pautas de conducta, que trae consigo para quienes se vinculan voluntariamente a ellos, determinadas obligaciones y derechos.

\section{Conclusiones}

De las consideraciones expuestas, se concluye que en principio, la práctica esperada de los Estados participantes debería ser la eliminación de restricciones al comercio ya sean unilaterales, o justificadas, tanto en el comercio regional como en el multilateral. La complejidad de las relaciones regionales y multilaterales, como se ha señalado es una situación latente, los esfuerzos para estudiarla, y encontrar respuestas, constituyen un reto. Dentro del marco de la OMC, se contempla la posibilidad de revisar las normas de los acuerdos regionales, para evaluar su consonancia con las reglas multilaterales, esa es una opción que es considerada como facultativa, y que en diciembre de 2006, fue retomada por el Comité de Acuerdos Comerciales Regionales (CACR). Ese sería un mecanismo que podría ayudar a evitar en lo sucesivo la ocurrencia de conflictos. Sin embargo, eso dependerá del impulso que le den los países. Así también, debe recordarse que hay instancias previas de consultas o negociaciones que pueden servir para ir aclarando una situación que pueda tornarse conflictiva.

El éxito de las relaciones comerciales internacionales depende en gran medida de la credibilidad que tengan los múltiples instrumentos jurídicos internacionales vigentes, de la observancia de los principios asumidos, no sólo en los términos clásicos de permitir el acceso a los mercados de bienes, servicios e inversión, sino también, la necesidad de brindar seguridades para el productor, el consumidor, el comerciante y el inversionista. Es pertinente mencionar la reflexión de Cardozo (1998:44) "en tiempos de globalización la política exterior es entonces parte de un sistema cada vez más complicado de transacciones locales, nacionales y mundiales", de las que puede afirmarse, no escapa ningún sector y la integración regional juegan un papel muy importante en los procesos de desarrollo. 
Los países siguen recurriendo a alianzas comerciales de distinto alcance, bilaterales, plurilaterales y multilaterales, mostrando su voluntad de asociación y cooperación, claro está, las asimetrías existentes, las realidades nacionales, y la necesidad de concordancias de los acuerdos en un escenario interdependiente, presionan en el cumplimiento de esos objetivos, en ese sentido, es un tema que seguirá siendo objeto de estudios en el área de las relaciones internacionales.

\section{Bibliografía}

Balassa, B. (1964). Teoría de la integración económica. México D.F: Uteha de Economía.

Cardozo, Elsa (1998). Cuarenta años después: la política exterior que tuvimos y la que necesitamos. Revista Venezolana de Análisis de Coyuntura, volumen IV, N 1, ene-junio (1998), 43-61.

Chahín Lizcano, G. (2004). Testimonio Comunitario. Robertson, Tamamés et al. En CD-168, Quito: Tribunal de Justicia de la Comunidad Andina.

Ferrer, A. (2007). Desarrollo e Integración: Desafíos y Oportunidades del MERCOSUR. Parte I y II. Revista Vértice, volumen $N^{o}$ 2, (2007), enero-febrero, año 1, Caracas: Banco de Comercio Exterior.

Grien, R. (1994). La Integración económica como alternativa inédita para América Latina. México D.F.: Fondo de Cultura Económica.

Hasenclever, Andreas, Mayer, Peter, y Rittberger, Volker (1999). Las Teorías de los Regímenes Internacionales: Una situación actual propuestas para una síntesis. Revista Foro Internacional, N 158, octubre-diciembre (1999), México D.F. Traducción de Lorena Murillo y Francisco J.J. Castro y Ortiz.

Hernández, R., Fernández, C. y Baptista, M. (2010). Metodología de la Investigación. México D.F.: Editorial McGraw Hill.

Hurtado, J. (2012). Metodología de la investigación holística. Caracas: Ediciones SYPAL.

Keohane R., Nye J.(1988). Poder e Interdependencia. Buenos Aires: Grupo Editor Latinoamericano. Colección Estudios Internacionales.

Lacarte, J. y Granados J.(2004). Solución de controversias intergubernamentales: Enfoques Multilaterales y Regionales. Buenos Aires: Banco Interamericano de Desarrollo (BID), Instituto para la Integración de América Latina y el Caribe (INTAL).

Mattli, W. (1999). The Logic of Regional Integration, Europe and Beyond. United Kingdom: Cambridge University Press.

Mattos, J. (2005). Lógica y Paradoja del libre comercio, Serie 45, CEPAL, Santiago de Chile: CEPAL p. 45.

Moavro, R. (1992). La Decisión. Caracas: Ediciones Nueva Política. 
Moncayo Jiménez, E. (1999). Las relaciones Externas de la Comunidad Andina. Entre la globalización y el regionalismo abierto. Lima: Secretaría General de la Comunidad Andina.

Obaya, M. (2005). ¿Qué puede decir la nueva economía institucional sobre los procesos de integración regional? Perspectivas Internacionales, $N^{o} 1$, año 1, Cali: Pontificia Universidad Javeriana, Observatorio de Asuntos Internacionales, 15-18.

Organización Mundial del Comercio (OMC) A. Base de datos de Acuerdos Comerciales Regionales notificados en OMC. http://rtais.wto.org/UI/PublicMaintainRTAHome.aspx_CConsulta: 2017, febrero 20].

Organización Mundial del Comercio (OMC). Novedades de los acuerdos comerciales regionales. https://www.wto.org/spanish/tratop_s/region_s/rtajuly-dec16_s.pdf. [Consulta: 2017, febrero 20].

Organización Mundial del Comercio (OMC). Novedades de los acuerdos comerciales regionales. https://www.wto.org/spanish/thewto_s/whatis_s/tif_s/bey1_s.htm [Consulta: 2017, febrero 20].

Oyarzun de La Iglesia, J. et al. (1998). Regionalismo vs. Multilateralismo: efectos de la Ronda Uruguay. Ponencia presentada en el Seminario Internacional sobre Integración Economía Regional (1997) Europa e Iberoamérica: dos escenarios de integración económica. Madrid: editorial Parteluz.

Pérez Gabilondo, J. (2004). Manual sobre solución de controversias en la Organización Mundial del Comercio. Buenos Aires: Editorial de la Universidad de Tres de Febrero.

Real Academia Española (2000). Diccionario de la lengua española. Vigésima primera edición, Madrid.

Rojas Aravena, F. y Almann, J. (2006). Multilateralismo e Integración en América Latina y el Caribe. Seminario Internacional: Paradojas de la Integración en América Latina. Santiago de Chile: CEPAL-FLACSO-Fundación Carolina, 13-14 de diciembre.

Romero, M. T. (2009). Política exterior venezolana. Caracas: Los libros de El Nacional.

Thurow (2000), citado por Torcuato Di Tella. La guerra del siglo XXI. ¿Qué se gana con la unidad sudamericana?, Buenos Aires: Universidad de Buenos Aires.

Tugores, J. (1999). Economía Internacional: Globalización e integración regional. Madrid: Mac Graw Hill.

Van Klaveren, A. (2001). Regionalismo y Multilateralismo: Una convergencia necesaria. Aldea Mundo, Mérida: Universidad de los Andes, mayo-junio. 